\section{Mobilising positive reinforcement to reduce youth access to tobacco}

\author{
Anthony Biglan, Jamye Henderson, Delaine Humphrey, Maija Yasui,
} Rebecca Whisman, Carol Black, Lisa James

\begin{abstract}
Objective - To evaluate a community intervention to mobilise positive reinforcement for not selling tobacco to young people.

Intervention - The intervention had five components: (a) mobilisation of community support; (b) education of merchants; (c) changing consequences to clerks for selling or not selling to those under 18 years; (d) publicity about clerks' refusals to sell; and (e) feedback to store owners or managers about the extent of their sales to adolescents.

Methods - Two multiple baseline design experiments were conducted, each involving two small communities in Oregon, USA. Stores' willingness to sell was assessed repeatedly by teenage volunteers (aged 15, 16, or 17 years). The intervention was introduced in one member of each pair of communities following three baseline assessments and in the second member, once clear effects were evident in the first community.

Results-The intervention significantly reduced the proportion of stores willing to sell and increased the proportion of clerks asking for proof of age.

Conclusion-Mobilising social and material reinforcement for stores not selling tobacco to young people is a viable means of reducing such sales. The approach may be especially valuable in communities where laws against sales to minors are inadequate or unenforced.
\end{abstract}

(Tobacco Control 1995; 4: 42-48)

Keywords: access to tobacco; sales, to minors; prevention, adolescents

\section{Introduction}

Reducing illegal sales of tobacco to adolescents is an important component of efforts to reduce teenage addiction to tobacco. Adolescents obtain a large proportion of their tobacco products through illegal purchases. Forster $e t$ $a l^{1}$ found that illegal purchases by people under 18 were possible $53 \%$ of the time in attempts to buy over the counter and $79 \%$ of the time through vending machines. Other studies have shown that teenagers succeed in buying tobacco products from $65 \%$ to $100 \%$ of the time $e^{2-6}$ Jason et $a l^{5}$ found that, in one community, adolescents' self-reported tobacco use was reduced by curbing illegal sales and fining minors in possession of tobacco. If we can make it more difficult for young people to obtain tobacco products, they may be less likely to become addicted.

The optimal intervention to reduce illegal sales would appear to involve law enforcement. Both Jason $e t a l^{5}$ and Feighery $e t a l^{7}$ found that active enforcement of laws prohibiting such sales increased the deterrent effect achieved through education and publicity of merchants. Unfortunately, obtaining the necessary laws or their enforcement may prove difficult. States may pass laws that pre-empt tobacco vendor licensing ordinances at the community level. Many jurisdictions are loath to enforce laws regarding tobacco sales and possession, ${ }^{7}$ citing the volume of other crimes with which they must deal. Strategies are needed to reduce sales in communities that will not (or cannot) use legal penalties.

The present intervention was derived from an analysis of consequences for the practice of selling tobacco to minors. To reduce the prevalence of this practice, one can increase the benefit-to-cost ratio for not selling to minors, or decrease the benefit-to-cost ratio for making such sales, or both. $\mathrm{McD}^{\mathrm{c}}$ owell ${ }^{8}$ has reviewed substantial evidence indicating that, where there is a choice between two behaviours such as selling or not selling tobacco, one can achieve equivalent effects by increasing the reinforcement and decreasing the punishment for the desired behaviour or decreasing the reinforcement and increasing the punishment for the problematic behaviour. Thus, in theory it should be possible to reduce sales to young people simply by increasing reinforcement for not selling to them, even where increases in penalties and reductions in reinforcement for selling cannot be achieved.

The benefits of selling tobacco to minors young people to whom it is sold, and the avoidance of aversive reactions from customers who are asked for identification. The costs of such sales could include civil and criminal penalties, and disapproval and loss of business from those who oppose such sales. Unfortunately, penalties are seldom imposed and those who might disapprove of sales are typically unaware of them and ill equipped to take action.

In contrast, there are few positive consequences for asking for proof of age or refusing to sell to young people. Although parents and influential community members may approve include profits, ${ }^{9}$ social reinforcement from 
of identity checks and refusals to sell, they are unlikely to know when these practices occur. Thus, clerks and store owners are unlikely to receive social approval or material benefits for obeying the law.

Based on this analysis, we developed a community intervention designed to mobilise social and material reinforcement for store owners and clerks who refused to sell tobacco to young people. The intervention had five components: (a) mobilisation of community support; (b) education of merchants; (c) changing consequences for clerks selling or refusing to sell tobacco; (d) publicity about clerks' refusals to sell; and (e) feedback to store owners or managers about the extent of their sales to adolescents. The changes in consequences involved increasing social and material reinforcement for clerks who refused to sell to young people and mild disapproval in the form of a reminder about the law to clerks who did sell to young people.

\section{Method}

\section{COMMUNITIES}

The study was conducted as part of an experimental evaluation of a community-wide programme to reduce the prevalence of tobacco and other substance use among youth. The experiment is being conducted in eight pairs of small communities (population 1700 to 13500) in Oregon, USA. One member of each pair is assigned at random to receive a programme in school grades 6 to 12 (ages 8-11) in the prevention of the use of tobacco and other substances. ${ }^{10,11}$ The other member receives a community intervention in addition to the school-based programme. The community intervention is composed of modules designed to assist community members in influencing adolescents not to use tobacco or other substances. Its implementation is led by a community coordinator who is a member of the community and an employee of Oregon Research Institute. One of those modules specifies a programme to reduce sales of tobacco to young people. The initial experimental evaluation of that module is reported here.

The table presents demographic data about the four communities that participated in the present experimental evaluation. Two communities, Florence and Reedsport, are on the Oregon coast. Their principal economic activities are logging and tourism. The module was initially evaluated in these two communities and, after refinements, implemented and evaluated in the second two communities. Sherwood is a farming community that is rapidly becoming a "bedroom community" of

Participating communities

\begin{tabular}{|c|c|c|c|c|c|c|c|}
\hline$=$ & \multirow[b]{2}{*}{ Community } & \multirow[b]{2}{*}{ Population } & \multirow[b]{2}{*}{$\begin{array}{c}\text { Minority } \\
\text { in school } \\
(\%)\end{array}$} & \multicolumn{4}{|c|}{ Stores } \\
\hline 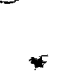 & & & & Convenience & $\begin{array}{c}\text { Grocery/ } \\
\text { variety }\end{array}$ & Other & Total \\
\hline$\leftarrow$ & $\begin{array}{l}\text { Florence } \\
\text { Reedsport } \\
\text { Sherwood } \\
\text { Hood River }\end{array}$ & $\begin{array}{l}5162 \\
4796 \\
3093 \\
4632\end{array}$ & $\begin{array}{r}7.2 \\
2.6 \\
2.2 \\
20.8\end{array}$ & $\begin{array}{l}9 \\
2 \\
7 \\
8\end{array}$ & $\begin{array}{r}5 \\
9 \\
11 \\
14\end{array}$ & $\begin{array}{l}1 \\
3 \\
4 \\
1\end{array}$ & $\begin{array}{l}15 \\
14 \\
22 \\
23\end{array}$ \\
\hline
\end{tabular}

Portland. Hood River is located on the Columbia River; its economy is dependent mainly on fruit growing and tourism.

\section{IDENTIFICATION OF TOBACCO OUTLETS}

Lists of businesses were obtained from the Chamber of Commerce or the city. Those thought likely to sell tobacco were visited to determine if they did. The table indicates the number and type of store in each community that sold tobacco products at the outset of work in that community.

In Sherwood, school district boundaries were such that students living in other communities went to the Sherwood schools. Because our ultimate goal is to reduce tobacco use among all students in the school districts, we implemented the present intervention in the greater Sherwood area by including stores from three adjacent communities.

Oregon law prohibits vending machines being accessible to those under age 18. Each of the communities was surveyed before the start of data collection to ensure that no vending machines were accessible to the young. In six instances, business owners were advised that vending machines needed to be moved to comply with the law. Compliance was obtained in every case.

DESIGN

The study consisted of two multiple baseline experiments. The first occurred in Florence and Reedsport. Assessments of the willingness of stores to sell to young people were conducted every three weeks. After three assessments, the intervention was begun in Florence. Following two additional assessments, the effect of the intervention was felt to be sufficiently clear that it was implemented in Reedsport. (The fifth assessment scheduled for Reedsport was not completed because youth assessors did not attend.)

A replication of this experiment was conducted in greater Sherwood and in Hood River beginning about eight months after the study began in the first two communities. Assessments were conducted every two weeks in these communities. Three baseline assessments were conducted in the greater Sherwood area and then the intervention was introduced. Following an additional five baseline assessments, the intervention was introduced in Hood River.

\section{MEASUREMENT}

The chief dependent variable was the proportion of stores in the community that were willing to sell tobacco to young people. At each assessment, one boy and one girl were recruited to attempt to buy tobacco. Data were also obtained on: (a) whether the clerk asked for identification; and (b) whether the clerk asked the assessor's age. 
were driven to each store by an adult. Boy and girl pairs went into each outlet, and alternated attempts to buy tobacco across stores. Boys attempted to buy smokeless tobacco on half of the occasions and cigarettes on the other half. Girls always attempted to buy cigarettes. The cigarettes to be purchased were either Marlboros or Camels. The brands of smokeless tobacco were Copenhagen or Kodiak.

Assessors were taught to enter the store, get a food item (such as a soft drink) and get, or ask for, a tobacco product. If the clerk agreed to sell the tobacco product, assessors indicated that they had insufficient money to pay for both items and declined to buy the tobacco product. This approach was taken because it is illegal for underage youth to possess tobacco in Oregon, and we did not want to be in a position of prompting an illegal act. If assessors were asked for identification, they were instructed to say that they did not have it with them. If they were asked their age, they were instructed to answer honestly. Assessors were also instructed to make, and keep, eye contact with the clerk, to reduce the likelihood that a youth's diffidence might prompt the clerk to refuse the sale.

To avoid arousing suspicion, new assessors were recruited at each assessment point. This was done to reduce the likelihood that clerks would realise an assessment was being done. This makes it possible that differences in young people's ability to buy were partly a function of their apparent age or other physical or behavioural characteristics. To minimise inter-assessor effects, we attempted to standardise their behaviour through training consisting of instruction and behaviour rehearsal. Training typically occurred on the day of the assessment.

Each assessor received a gift certificate, worth about $\$ 5$, for every hour of participation.

\section{Measures}

The following information was recorded for each outlet: (a) name of outlet; (b) type of outlet (variety store, convenience store/petrol station, other); (c) gender of the clerk; (d) type (cigarettes or smokeless tobacco) and brand of tobacco product asked for; (e) whether the tobacco was behind the counter or accessible to customers; (f) whether identification was requested; (g) whether the youth was asked his or her age; and (h) whether the clerk was willing to sell tobacco. In Florence and Reedsport, assessors completed this form collaboratively. To assess reliability, assessors in the Sherwood area and in Hood River filled out the form without consulting each other. In both Hood River and greater Sherwood, there was $100 \%$ agreement about whether or not (a) the clerk asked for identification, (b) the clerk asked the assessor's age, and (c) the clerk was willing to sell.

\section{INTERVENTION}

The groundwork for the overall community intervention was laid through extensive com- munication to civic leaders regarding the need to prevent adolescents using tobacco. These leaders were told about the evidence that cigarette smoking is the main preventable cause of disease and death and that preventing adolescents from using tobacco was important because most smokers become addicted as teenagers. The health hazards of smokeless tobacco use were also described. These same messages subsequently were communicated as widely as possible in the community. Media communication included press releases and feature stories in newspapers, radio advertising, and the distribution of pamphlets encouraging parents to talk to their children about not using tobacco. In addition, a mailing list was created of civic leaders interested in receiving monthly "fact sheets" about the tobacco problem.

Pilot development of this intervention took place in Florence in the year before the intervention described here. A committee of interested adults worked with the Community Coordinator $(\mathrm{JH})$ to develop and implement a programme to get stores to stop selling tobacco to minors. That intervention consisted of visits to each outlet in which the store owner or manager was briefed on the law and given a packet containing materials and signs regarding the illegality of tobacco sales to minors. Each outlet received a follow-up visit where more materials and assistance were offered. Based on purchases that young-looking 18year-olds made, there was little evidence that the intervention had an effect. It was therefore revised to include the five components described below.

\section{Mobilisation of community support}

Public support of a campaign to eliminate sales to minors was sought from city government, the school district, health care providers, civic organisations, social welfare agencies, churches, major businesses, and all tobacco outlets. Initially a letter and a copy of a proposed proclamation were sent to organisations. The letter was signed by the community coordinator and, in some communities, by other community leaders. It asked that community members and organisations lend their names to the proclamation supporting no sales to minors. The letter was followed by calls or visits from the community coordinator or other community members. The proclamation was published in the local newspaper and distributed to tobacco merchants.

This process produced substantial support in each community. In Florence, 10 of the 15 tobacco outlets and 36 other organisations endorsed the proclamation. In Reedsport, 45 prominent individuals, 11 tobacco outlets, 12 other businesses, and nine civic groups endorsed the proclamation. In Hood River 122 persons and organisations signed the proclamation, including the County Commission, the Mayor and City Council, the County Administrator, both county and city police chiefs, judges, school district superintendents, hospital administrators, attorneys, doctors, 
and heads of major local businesses. In the Sherwood area, 202 people and organisations signed the proclamation. Most people who signed were from Sherwood.

Mobilisation of community support began during baseline and continued throughout the intervention. As progress was made on the intervention, publicity for the success of the campaign was sought to maintain community support and encourage community members to give positive feedback to merchants.

\section{Merchant education}

At the outset of the campaign, each tobacco outlet was visited. The owner or manager was given a packet that contained a description of the law that could be passed on to clerks, a copy of the proclamation, and signs regarding no sales to minors that could be posted in the store. Retailers were told about the continuing assessments of tobacco sales and about the plan, described below, to reward clerks for asking for identification and refusing to sell to young people.

\section{Reward and reminder visits}

Clerks who asked for identification or refused to sell to minors, or both, were rewarded with gift certificates and public recognition. Teenagers who were part of the project attempted to buy tobacco, following the procedures described in the measurement section. If the clerk asked for identification or refused to sell the item, the young person handed her or him an envelope containing a gift certificate and a letter thanking them for refusing to sell. Gift certificates were typically donated by local businesses, were worth from $\$ 2$ to $\$ 10$, and could be redeemed against food items or meals in local restaurants. Clerks who were willing to
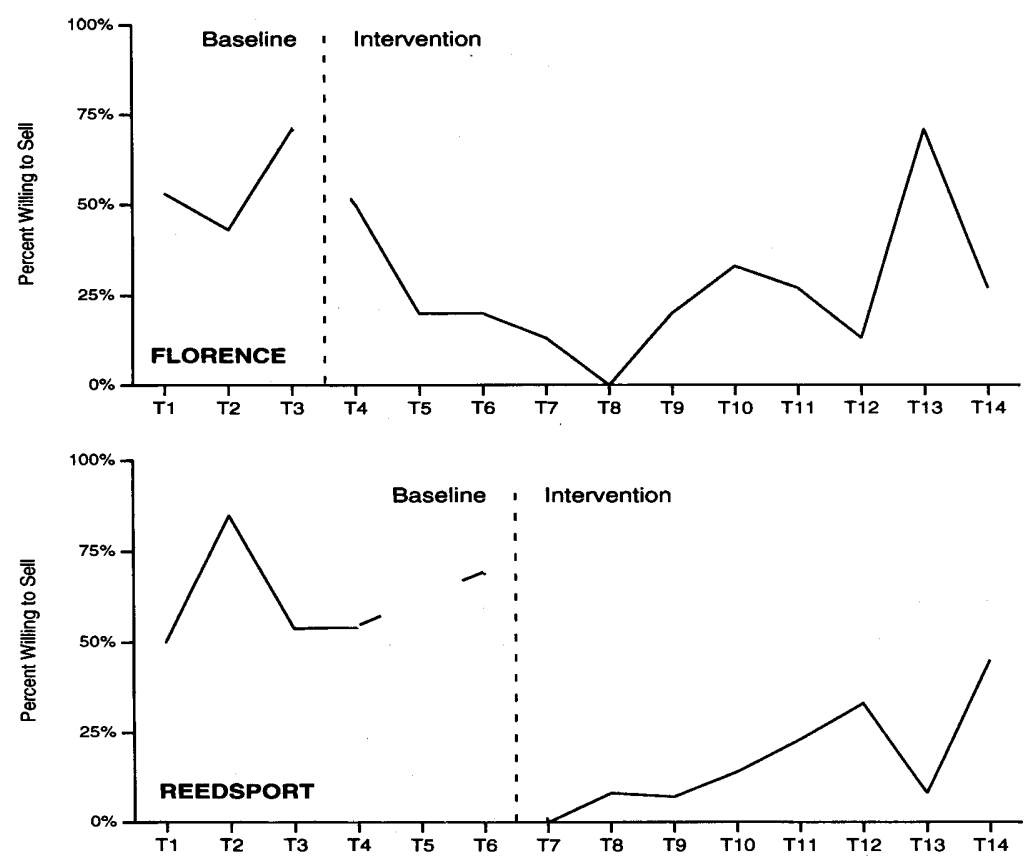

Figure 1 Proportion of outlets willing to sell tobacco in Florence and Reedsport sell received statements reminding them that it was illegal to sell tobacco to those under 18 and that the community supported adherence to this law. The statement asked them to request identification in the future.

These visits were made to each store once the intervention began. They were distinct from the assessment visits, which did not provide any feedback to clerks about their behaviour. Frequency of intervention visits was curtailed as stores' willingness to sell declined.

Publicity about clerks' refusals to sell

To provide social recognition to clerks for their refusals to sell to minors, newspaper articles, paid advertisements, and circulars were used to publicise instances where clerks had refused to sell tobacco when the teenagers gave the reward described, and paid reminder visits. Their pictures were published with the caption: "These clerks were caught in the act". The story went on to describe how the clerk had asked for identification and received a gift certificate.

\section{Feedback to outlets}

Tobacco outlet owners and managers received feedback about the extent to which clerks in their store had refused or been willing to sell. Identities of specific clerks were not revealed. Publicity that stores had received for not selling was also shared with outlet representatives. If stores continued not selling, the frequency of feedback diminished. Stores that continued to sell continued to receive visits. In the Sherwood area, the level of sales continued to be high for the first to fourth assessments after implementation of the intervention. Therefore, beginning with the fifth intervention phase assessment, each store was visited with follow-up information after each assessment.

\section{Results}

EXPERIMENT 1

Figure 1 presents the results of the intervention in Florence and Reedsport. The proportion of stores willing to sell at each assessment is shown. In both communities, the introduction of the intervention was associated with a sharp drop in the proportion of stores willing to sell. In Florence, an average of $57 \%$ of stores were willing to sell across baseline assessments. Across all post-intervention assessments, the average was $27 \%$. (A single data point during intervention - T13 - was substantially higher than all others due to older looking assessors.) In Reedsport the mean proportion of stores willing to sell was $62 \%$ during baseline but fell to $17 \%$ during the intervention.

These reductions were accompanied by increases in the proportion of stores that asked for identification. The baseline average proportion of stores asking for identification in Florence was $35 \%$; it was $58 \%$ during the intervention phase. In Reedsport, $25 \%$ of 

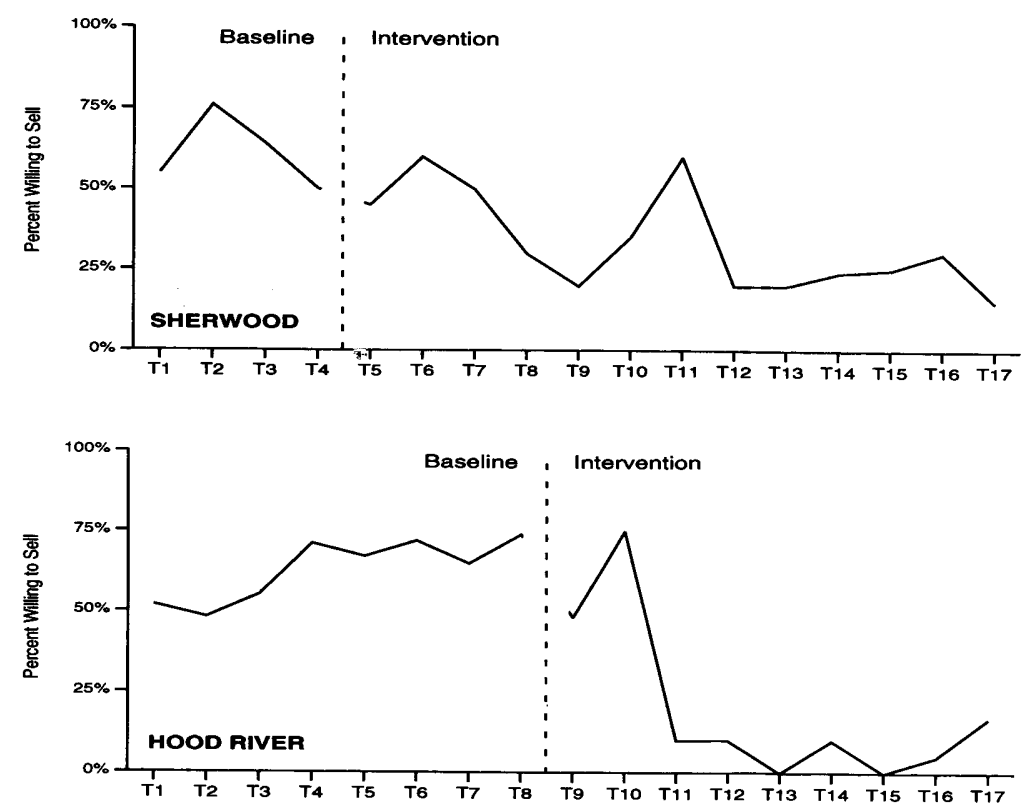

Figure 2 Proportion of outlets willing to sell tobacco in Sherwood and Hood River

stores asked for identification during baseline, whereas $68 \%$ did so during intervention.

\section{EXPERIMENT 2}

Figure 2 presents data for the Sherwood area and for Hood River. The intervention was introduced in the Sherwood area following three baseline assessments. The proportion of stores willing to sell decreased from $65 \%$ at baseline to $35 \%$ in intervention. The proportion of stores asking for identification averaged $38 \%$ at baseline and $65 \%$ across intervention assessments. These effects were not as substantial as those in Florence and Reedsport. Further inspection of the data indicated that the intervention was more effective in Sherwood than in the communities surrounding Sherwood. There were three stores in Sherwood. During baseline an average of $67 \%$ of these stores were willing to sell. During intervention the average was $7 \%$ and none of the stores sold during the last 11 assessments. These stores asked for identification $33 \%$ of the time in baseline and $90 \%$ of the time in intervention $100 \%$ of the time in the last 11 assessments). In contrast, baseline average proportion of stores selling was $64 \%$ in communities surrounding Sherwood. The average dropped to $38 \%$ during intervention. The figures for those asking for identification were $39 \%$ in baseline and $54 \%$ in intervention.

The intervention was introduced in Hood River once there was evidence of its effect in the Sherwood area (figure 2). The mean proportion of stores willing to sell at baseline was $63 \%$. The mean across all post-intervention assessments was $19 \%$; it was $17 \%$ or lower after the first month of intervention. During baseline an average of $25 \%$ of the stores asked for identification. Across intervention assessments it was $70 \%$.

Statistical test of the effects of intervention Crosbie $^{12}$ has developed a statistical test for interrupted time-series analysis data with small numbers of observations in one or more phases. The key feature of time-series analyses is that they must correct for the autocorrelation in the data, before testing for differences between phases with parametric statistics. Crosbie ${ }^{12}$ has shown that his procedure (ITSACORR) provides an appropriate correction for auto-correlations providing that there are at least five data points in each phase.

In the present case, we had only three data points in the baseline phase in two of the communities. We therefore combined the data across the four communities and tested the effects of intervention across all communities. Thus, the mean percentage of stores willing to sell tobacco was averaged across communities at each assessment.

Crosbie's ${ }^{12}$ analysis allows two statistical tests, one for the difference in slope between baseline and intervention, the other for the difference in the intercept for the two phases. We found that the slope in baseline did not differ significantly from the slope in intervention. The intercept in intervention, however, was significantly lower than the intercept in baseline, $t(12)=-2.33, \mathrm{p}=0.038$. Thus across the four communities, the level of sales was significantly lower after the intervention was introduced.

\section{EFFECT OF CHARACTERISTICS ON THE OUTCOME} OF PURCHASE ATTEMPTS

We examined whether the gender or age of the clerk or the gender of the assessor influenced the outcomes of the purchase attempts. To do this we combined the data from all purchase attempts across all communities. There was a total of 1597 purchase attempts.

It should be noted that this introduces some redundancy in the data because, especially in smaller outlets, the same clerk may have been assessed more than once. Moreover, at any given assessment, the young people assessed all the outlets in the community. For these reasons, one should probably require a smaller alpha in these analyses.

The gender of the assessor was not significantly correlated with the willingness of clerks to sell. There was a slight, though significant tendency for male clerks to be more willing to sell, $r=-0.06, \mathrm{p}=0.013$. There was no evidence of an interaction between the gender of the clerks and the gender of the assessors. In other words, there was no tendency for clerks of one gender to be more willing to sell to one gender of teenager more than the other.

SALES OF CIGARETTES VS SMOKELESS TOBACCO TO BOYS

There was a significantly greater willingness to sell smokeless tobacco than cigarettes to boys. Clerks were willing to sell cigarettes in $33 \%$ of occasions, whereas they were willing to sell smokeless tobacco on $40 \%$ of occasions (FCG $\mathrm{c}=4.01(1 \mathrm{df}), \mathrm{p}<0.045)$. 


\section{Discussion}

The results suggest that illegal sales of tobacco to young people can be reduced, even where penalties for law violation are not imposed. Across the four communities the average sales rate in baseline was $62 \%$ and it dropped to $24 \%$ in the intervention phase. For comparison, Altman et $a l^{2}$ found that $76 \%$ of outlets sold tobacco in pretest assessments, $39 \%$ sold six months after a merchant education programme, and $59 \%$ sold a year after the introduction of the programme. By mobilising social and material reinforcement for the practice of not selling, a substantial decrease in such sales was achieved in each community. This strategy may be valuable in communities where inducing law enforcement agencies to enforce the law proves difficult. Many jurisdictions are loath to enforce laws regarding tobacco sales and possession. ${ }^{7}$ Police complain that judges often are not supportive of hearing such cases. We would hope that media advocacy about the importance of preventing tobacco use will influence the judicial system to view violations of these laws more seriously. As long as resistance to enforcing these laws exists, however, the methods described in this paper may be needed.

Each of the five components of our intervention may have contributed to its effects. Mobilisation of visible community support for not selling to minors may have made public disapproval of such sales more salient. Merchant education served this function and elicited a commitment from owners and managers not to sell. Gift certificates and publicity for clerks who refused to sell increased reinforcement for this behaviour. Delivery of reminders when they were willing to sell probably constituted a mild punishment. Feedback to stores that continued to sell was probably aversive to store owners and may have prompted them to discontinue their own sales to minors and increase their efforts to affect the behaviour of their clerks.

It is possible that fear of law enforcement contributed to these results. Clerks and merchants may have feared that their failure to comply with the present programme would lead to citations for sales. At no point did we suggest that such enforcement would follow and, although law enforcement officials were generally supportive of our efforts, they did not threaten law enforcement.

The results also suggest that continued intervention will be needed, if reductions in illegal sales are to be maintained. In two communities, there was a tendency toward increased sales as the intervention activities were reduced.

It is unclear to what extent this programme could be mounted without the support of a funding agency. In principle it would be possible for a single adult volunteer to organise, train, and supervise young people in doing the reward and reminder visits. Rewards appear to be readily attainable from local merchants. Publicity about the programme also appears readily attainable. The extensive assessments that we conducted, however, would probably be too much for even the most motivated volunteer. It is conceivable that the programme could be done with many fewer assessments. Indeed, the reward and reminder visits could be used to assess the effects of the campaign.

Finally it should be noted that these results may be easier to attain in the small communities we worked with than in larger ones. Replication of the study in cities would be valuable.

VALUE OF TIME-SERIES EXPERIMENTAL DESIGNS

The design of our study is an example of the use of time-series experimentation in whole communities. Evidence of the effect of the intervention is assessed in two ways. Firstly, a change between baseline and intervention in the level or slope of the repeated measures in the target community indicates an effect of the intervention. Secondly, if there is no change in slope or level of repeated assessments in communities that continue in the baseline phase of the experiment, it further strengthens our confidence that the effect was due to the intervention and not to extraneous events.

Such designs have been used extensively in clinical research, ${ }^{13}$ in education, ${ }^{14,15}$ and in the experimental analysis of behaviour, ${ }^{16}$ but have been little used in community intervention research. This is unfortunate, as the traditional alternative, a randomised controlled trial, is quite costly when the unit is an entire community.

Single case experimental designs are suitable whenever the dependent variable can be repeatedly measured over time. They have the potential to enable community interventionists to evaluate programmes in a small number of communities or even a single community.

POSSIBLE LIMITATIONS OF THE STUDY

The use of different assessors at each assessment could have affected the results of the study. For example, if all assessors following intervention looked significantly younger than assessors used during baseline, lower rates of willingness to sell would have resulted that were not due to genuine changes in store practices. This explanation of the results seems unlikely, because there were numerous baseline assessments, the actual ages of the young people did not vary between conditions, and informal assessments of the apparent ages of assessors did not indicate that they varied from baseline to intervention. Moreover, if the same assessors had been used, the problem would have been/worse, as clerks would soon have discerned who these people were and could have refused to sell to them, while continuing to sell to other young people.

Most of the assessors in the present study were 16 or 17 years old. Some previous studies have used assessors as young as $11 .^{5}$ Use of children underscores the extent and seriousness of the problem of sales to youth. However, using pre-teen assessors leaves open the possibility that interventions will not affect sales to 
young people who are closer to the legal age for sales. Using 16 and 17 year olds gives us greater confidence that the campaign reduced sales to these older, yet still underage, adolescents.

The authors would like to thank the 104 teeagers who conducted the assessments in this study and the many adults in Florence, Reedsport, Sherwood, and Hood River who contributed to the design of the intervention and the implementation of the design of the intervention and the implementation of this
evaluation. This research was supported by Grant No. CA38273 from the National Cancer Institute.

1 Forster JF, Klepp KI, Jeffery RW. Sources of cigarettes for enth graders in two Minnesota cities. Health Educ Res $1989 ; 4: 45-50$

2 Altman DG, Rasenick-Douss L, Foster V, Tye, JB. Sustained effects of an educational program to reduce sales of cigarettes to minors. Am J Public Health 1991; 81: 891-3.

3 Erickson AD, Woodruff SI, Wildey MB, Kenney E. A baseline assessment of cigarette sales to minors in San
Diego, California. F Commun Health 1993; 18: 213-24.

4 Forster JL, Hourigan ME, McGovern P. Availability of cigarettes to underage youth in three communities. Prev cigarettes to underage

5 Jason LA, Ji PY, Anes MD, Birkhead SH. Active enforcement of cigarette control laws in the prevention of cigarette sales to minors. FAMA 1991; 226: 3159-61.

6 Keay KD, Woodruff SI, Wildey MB, Kenney EM. Effect of a retailer intervention on cigarette sales to minors in San Diego County, California. Tobacco Control 1993; 2 : 145-51.

7 Feighery E, Altman DG, Shaffer G. The effects of combining education and enforcement to reduce tobacco sales to minors: A study of four northern California communities. FAMA 1991; 266: 3168-71.

$8 \mathrm{McD}$ owell, JJ. Matching theory in natural human environments. F Behav Anal 1988; 11: 95-109.

9 DiFranza JR, Tye JB. Who profits from tobacco sales to children? $\mathcal{F} A M A 1990 ; 263: 2784-7$.

10 Ary DV, Biglan A, Glasgow R, et al. The efficacy of socialinfluence prevention programs versus "standard care". Are new initiatives needed? $f$ Behav Med 1990; 13: Are new

11 Biglan A, James LE, LaChance P A, Zoref L, Joffe J Videotaped materials in a school-based smoking prevention program. Prev Med 1988; 17: 559-84.

12 Crosbie, J. Interrupted time-series analysis with brief single-subject data. fCCP 1993; 61: 966-74.

13 Barlow DH, Hayes SC, Nelson RM. The empirical clinician. New York: Pergamon, 1983.

14 Cook TD, Campbell DT Quasi-experimentation: design and analysis issues for field settings. Chicago: Rand McNally, 1979.

15 Kratochwill TR. An alternative research strategy for school psychologists. F School Psychol 1977; 15: 239-49.

16 Sidman M. Tactics of scientific research. New York: Basic Books, 1960. 